\title{
Low convergence of hepatic ducts: A rare extrahepatic biliary tree anatomical variation
}

\author{
Dayang Azzyati Awang Dahlan, Nik Azim Nik Abdullah, \\ Rokayah Julaihi
}

\begin{abstract}
Introduction: Low convergence of hepatic ducts is extremely rare. Here, the right and the left hepatic ducts course down towards the second part of the duodenum separately and converge just proximal to the ampulla of Vater, forming a short common bile duct. Case Series: We describe 2 cases of a 43-year-old male and a 53-yearold female with this anatomical anomaly who presented with obstructive jaundice. Endoscopic retrograde cholangiopancreatography (ERCP) demonstrated low convergence of the hepatic ducts. Both cases were associated with biliary ectasia and complicated with primary ductal stones. Excision of the anomalous extrahepatic bile ducts with hepaticoenterostomy was performed for one of the cases, however the other was lost to follow-up. Conclusion: Definitive operative intervention seems prudent despite
\end{abstract}

Dayang Azzyati Awang Dahlan', Nik Azim Nik Abdullah², Rokayah Julaihi ${ }^{3}$

Affiliations: 'Surgical Registrar, Department of Surgery, Sarawak General Hospital, Kuching, Sarawak, Malaysia; ${ }^{2}$ Consultant Hepatobiliary Surgeon and Head of Department, Department of Surgery, Sarawak General Hospital, Kuching, Sarawak, Malaysia; ${ }^{3}$ General Surgeon, Department of Surgery, Sarawak General Hospital, Kuching, Sarawak, Malaysia.

Corresponding Author: Dayang Azzyati Awang Dahlan, Complete Mailing Address: Lot 9265, Lorong Kenanga 5, Jalan Kenanga, Gita, Petra Jaya, Kuching, Sarawak, Malaysia - 93050; Ph: +060168788094; Fax: +06082419495; Email: azzyati@hotmail.com

Received: 05 May 2015

Accepted: 17 July 2015

Published: 16 September 2015 the lack of consensus in the management of such anomaly, especially when there are concomitant biliary ectasia and ductal stones.

Keywords: Biliary stone disease, Distal bifurcation, Extrahepatic biliary tract, Hepatic ducts, Low convergence

\section{How to cite this article}

Dahlan DAA, Abdullah NAN, Julaihi R. Low convergence of hepatic ducts: A rare extrahepatic biliary tree anatomical variatio. Int $\mathrm{J}$ Hepatobiliary Pancreat Dis 2015;5:92-96.

Article ID: 100041IJHPDDD2015

$$
* * * * * * * * *
$$

doi:10.5348/ijhpd-2015-41-CS-16

\section{INTRODUCTION}

Anatomical variations of the biliary tree are not uncommon and numerous anomalies have been described in literature. The right and the left hepatic ducts converge to form the common hepatic duct just after exiting the liver hilum in $60-70 \%$ of the cases [1]. However, low convergence of the hepatic ducts is extremely rare and the exact incidence is unknown with review of literature resulted in only a few case reports [2, $3]$. Here, the right and the left hepatic ducts course down towards the second part of the duodenum separately and converge just proximal to the ampulla of Vater, forming a short common bile duct. This may become significant 
during operative intervention as failure to recognize such anomaly may lead to iatrogenic biliary injury.

\section{CASE SERIES}

Case 1: A 43-year-old male was presented with epigastric pain and obstructive jaundice. Ultrasonography (USG) showed a normal liver and gallbladder with dilated common bile duct (CBD) and intrahepatic ducts (IHD) secondary to choledocholithiasis. Endoscopic retrograde cholangiopancreatography (ERCP) confirmed these findings (Figure 1). The ERCP with attempted stone extraction was challenging, made difficult by the presence of a huge pre-pyloric gastric ulcer. Thus a biliary stent was inserted to temporarily relieve the obstruction. He underwent open cholecystectomy and CBD exploration. Intraoperatively, the CBD was dilated with multiple soft stones within. Cholangioscopy confirmed no residual stones. Intraoperative biliary stenting was done. $\mathrm{He}$ recovered uneventfully and the biliary stents were removed two months later. Endoscopic retrograde cholangiopancreatography revealed the presence of low convergence of the hepatic ducts (Figure 2). The patient was counseled for operative intervention but was not keen and subsequently was lost to follow-up.

Case 2: A 53-year-old female who had previous open cholecystectomy for empyema of the gallbladder 16 years ago presented with epigastric pain and obstructive jaundice. The ERCP revealed low convergence of the hepatic ducts with a large stone in the left hepatic duct (Figure 3). Both the hepatic ducts and the CBD were grossly dilated and ectatic necessitating biliary stenting. Computed tomography (CT) scan showed normal liver, mild dilatation of the IHD with marked dilatation of the left and right hepatic ducts and CBD. Cholangiojejunostomy was performed and intraoperatively, both the hepatic ducts and CBD were dilated with 1 large stone in the left hepatic duct, measuring $2.5 \times 1.5 \mathrm{~cm}$ and 2 smaller stones in the right hepatic duct, measuring 1.0x1.0 $\mathrm{cm}$. Both hepatic ducts were transected as proximal as possible close to the lower liver edge. The medial edges of the ducts were sutured with interrupted polyglyconate sutures Maxon $^{\mathrm{TM}} 4 / \mathrm{o}$ to fashion a single duct and a retrocolic cholangiojejunostomy was created (Figure 4 and Figure 5). Histopathological examination of the hepatic ducts and CBD showed chronic inflammation. Subsequent follow-ups found she was well with no stone recurrence.

\section{DISCUSSION}

Anatomical variations of the biliary tree are not uncommon and numerous anomalies have been described in literature, based on observation from imaging studies, operative reports and autopsy discoveries, in as high as $47 \%$ of the cases [4]. These anomalies may be minor or major with variable clinical significance.

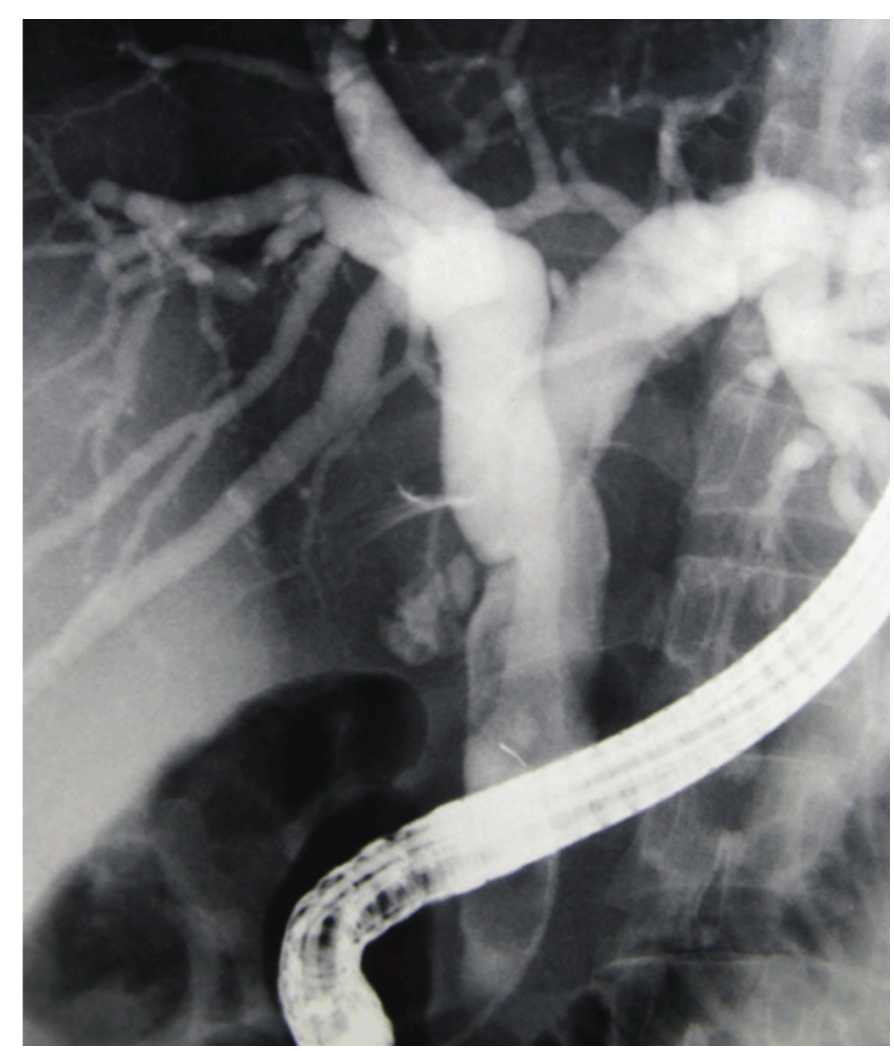

Figure 1: Cholangiogram demonstrating the insertion of the cystic duct into the right hepatic duct.

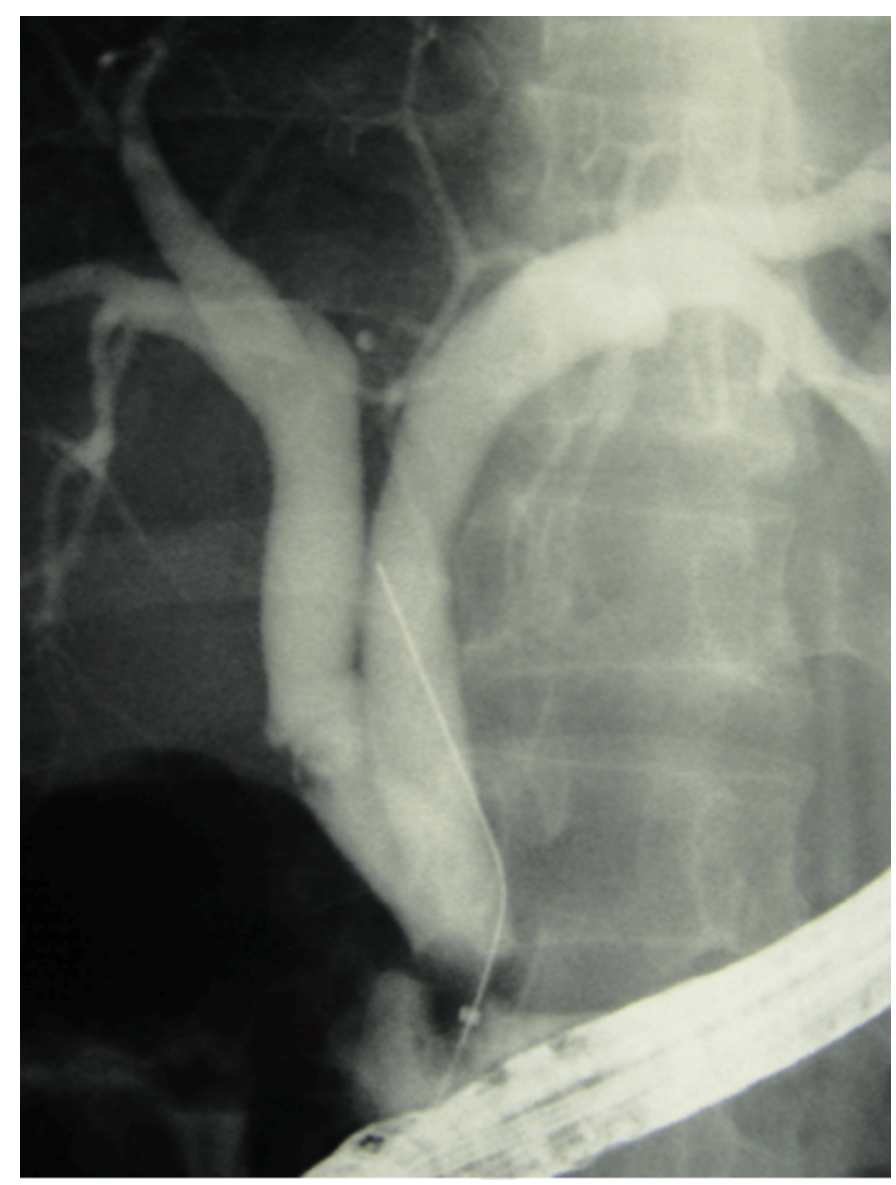

Figure 2: Cholangiogram demonstrating the long right and left hepatic duct converging to form the short common bile duct; note that the intrahepatic ducts are no longer dilated. 


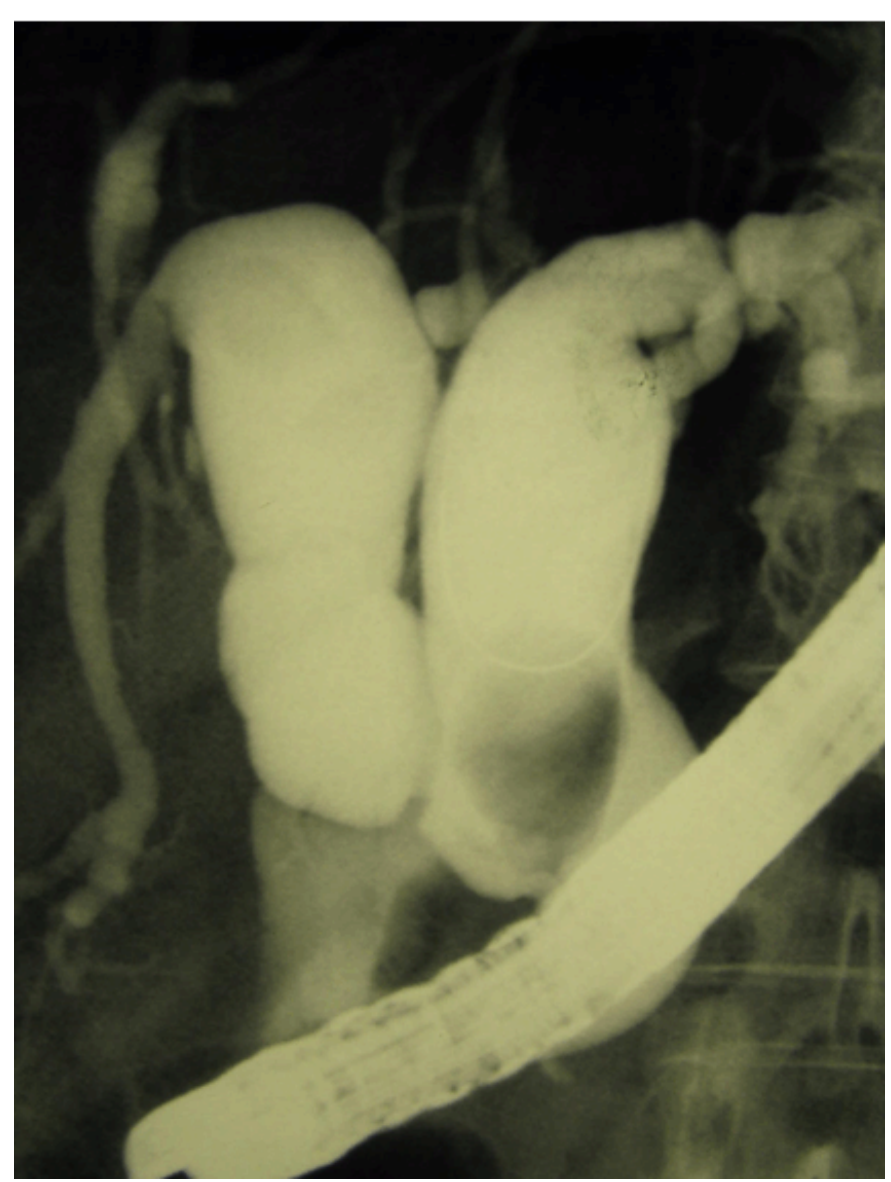

Figure 3: Cholangiogram demonstrating the grossly dilated right and left hepatic ducts.

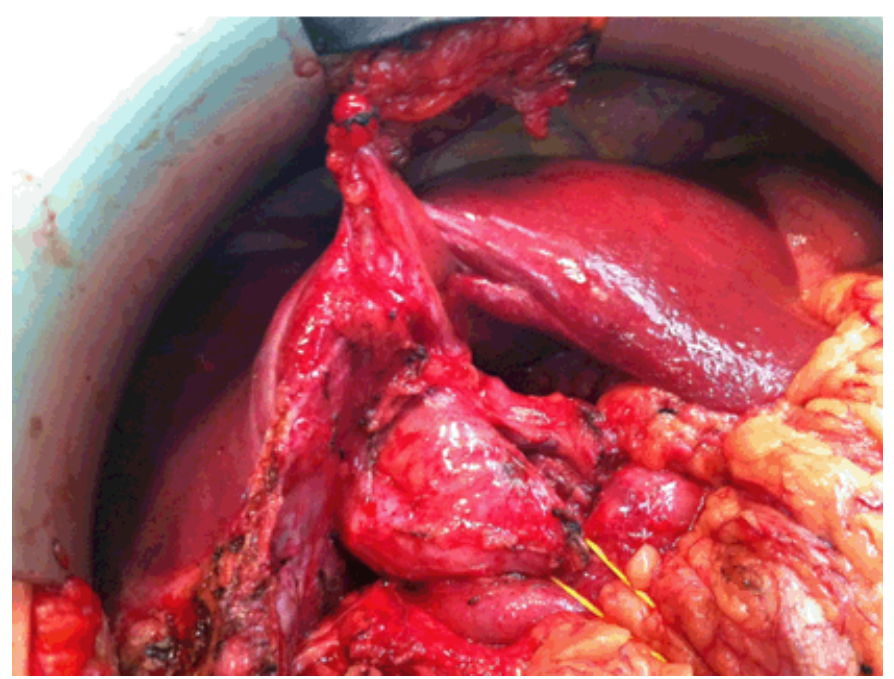

Figure 4: Intraoperative image showing the grossly dilated right and left hepatic ducts.

The numerous anatomical variations and anomalies are attributable to the underlying complexity of the embryological development of the liver and biliary tree. By the fifth week of intrauterine life, the liver, biliary tract, gallbladder and pancreas are recognizable structures. During this period, lengthening of the common duct occurs. However, the lumen is occluded by the rapidly

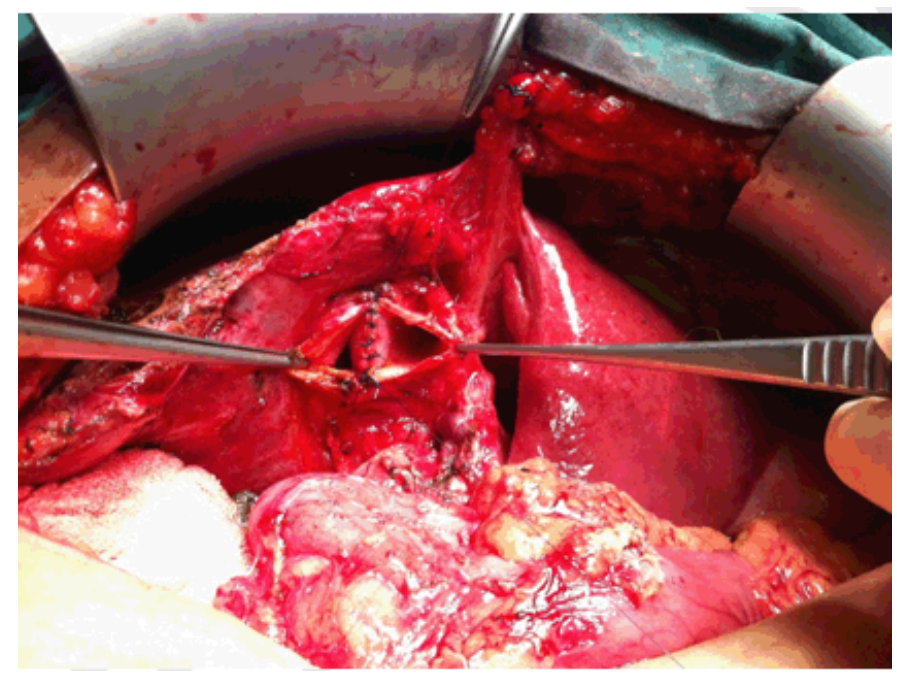

Figure 5: Medial edges of the ducts sutured to fashion a single duct before creation of the retrocolic cholangiojejunostomy.

proliferating epithelial cells. By the end of the fifth week, recanalization occurs and this start from the proximal portion progressing towards the distal portion of the lumen. By the eighth week, the common duct becomes patent and by 12th week, bile starts to flow from the liver to the second part of the duodenum [5].

The right and the left hepatic ducts converge to form the common hepatic duct just after exiting the liver hilum in $60-70 \%$ of the cases [1]. Low convergence of the hepatic ducts is extremely rare and resulted in longer than usual right and left hepatic ducts with resultant shorter than usual common bile duct. The common hepatic duct may or may not be present, depending on the site of insertion of the cystic duct. Frequently, the site of insertion of the cystic duct is anomalous too. Similar to one of our case, the cystic duct may insert to the right hepatic duct. Insertion to the left hepatic duct or low insertion to the more distal portion of the common bile ductal has been reported too $[2,3]$.

Such anomalies are postulated to be the result of embryological malformations, either due to incomplete recanalization or maldivision of the extrahepatic ductal portion of the embryonic hepatic diverticulum $[5,6]$.

Clinical presentation of such biliary tree anomalies includes recurrent abdominal pain, jaundice and fever due to biliary stone disease, cholangitis or pancreatitis. Frequently, these anomalies are discovered during the investigations and management of the presenting symptoms. The importance of recognizing such anomalies during surgical procedures such as laparoscopic cholecystectomy, is emphasized as failure to do so may result in iatrogenic biliary tract injury with resultant bile leak and ductal stricture $[7,8]$.

Both of our cases underwent open cholecystectomy under emergency setting as part of the management of their presenting symptoms. However, intraoperatively the anomaly was missed. This may be due to the presence of inflammatory and oedematous tissues or fibrous 
adhesions surrounding the extrahepatic bile ducts making the anomaly less obvious. For the first case, the initial ERCP did not reveal obvious low convergence due to the orientation of the film. This was subsequently detected in the later ERCP.

Biliary tree anomalies may predispose to formation of biliary stones [9]. Both of our patients presented with complications of primary ductal stone. In our cases, we believe such anomalous arrangement may cause abnormal bile flow or bile stasis. We postulated that the long hepatic ducts lie in the edge of the lesser omentum unsupported by solid liver parenchyma and an increase in the intraluminal pressure (i.e., secondary to stone obstruction) will easily stretches the ductal wall and causes ductal dilatation. This perpetuates the vicious cycle of biliary stasis, infection, further stones formation and obstruction.

The presence of recurrent and chronic biliary stones is associated with carcinoma of the biliary tract in the long term [10-11]. Biliary stones may initiate the hyperplasiacarcinoma sequence. As mentioned, it causes bile obstruction and stasis predisposing to infection. These conditions induce chronic inflammation via prolonged exposure of the epithelial cells to bile acids and pancreatic enzymes in the bile. These cause increased cellular proliferation, initiating the multistep progression from epithelial hyperplasia to metaplasia, then dysplasia and finally carcinoma of the biliary tract $[10,12]$.

Hence, a definitive operative intervention seems prudent despite the lack of consensus in the management of such anomalies, especially in cases with concomitant biliary ectasia and ductal stones. We felt that the decision for definitive management was challenging due to the scarcity of similar cases in literature. We decided to extrapolate the management from the management of adult choledochal cyst. Total excision of the extrahepatic bile duct and gallbladder followed by hepaticoenterostomy is the treatment of choice.

\section{CONCLUSION}

Low convergence of hepatic ducts is extremely rare. Such anomaly may be associated with biliary ectasia and ductal stones. Not only it predisposes the patients to recurrent obstruction, infection and pancreatitis, in the long-term it may also lead to carcinoma of the biliary tract. Definitive operative intervention seems prudent, especially in our cases where there are concomitant biliary ectasia and ductal stones.

$* * * * * * * * *$

\section{Author Contributions}

Dayang Azzyati Awang Dahlan - Substantial contributions to conception and design, Acquisition of data, Analysis and interpretation of data, Drafting the article, Revising it critically for important intellectual content, Final approval of the version to be published
Nik Azim Nik Abdullah - Analysis and interpretation of data, Revising it critically for important intellectual content, Final approval of the version to be published Rokayah Julaihi - Analysis and interpretation of data, Revising it critically for important intellectual content, Final approval of the version to be published

\section{Guarantor}

The corresponding author is the guarantor of submission.

\section{Conflict of Interest}

Authors declare no conflict of interest.

\section{Copyright}

(C) 2015 Dayang Azzyati Awang Dahlan et al. This article is distributed under the terms of Creative Commons Attribution License which permits unrestricted use, distribution and reproduction in any medium provided the original author(s) and original publisher are properly credited. Please see the copyright policy on the journal website for more information.

\section{REFERENCES}

1. Crawford JM. Development of the intrahepatic biliary tree. Semin Liver Dis 2002 Aug;22(3):213-26.

2. Koruk I, Aydin Ü, Koruk S, Aydinli M. A newly defined biliary anatomic variation. Turk J Gastroenterol 2011;22(2):232-3.

3. Häfner M, Schöfl R, Gangl A. A rare anomaly of the biliary tree: the interhepatic duct. Gastrointest Endosc 1997 Jun;45(6):523-5.

4. Lamah M, Dickson GH. Congenital anatomical abnormalities of the extrahepatic biliary duct: a personal audit. Surg Radiol Anat 1999;21(5):325-7.

5. Ando H. Embryology of the biliary tract. Dig Surg 2010;27(2):87-9.

6. Roskams T, Desmet V. Embryology of extra- and intrahepatic bile ducts, the ductal plate. Anat Rec (Hoboken) 2008 Jun;291(6):628-35.

7. Talpur KA, Laghari AA, Yousfani SA, Malik AM, Memon AI, Khan SA. Anatomical variations and congenital anomalies of extra hepatic biliary system encountered during laparoscopic cholecystectomy. J Pak Med Assoc 2010 Feb;6o(2):89-93.

8. Hasan MM, Reza E, Khan MR, Laila SZ, Rahman F, Mamun MH. Anatomical and congenital anomalies of extra hepatic biliary system encountered during cholecystectomy. Mymensingh Med J 2013 Jan;22(1):20-6.

9. Kubota Y, Yamaguchi T, Tani K, et al. Anatomical variation of pancreatobiliary ducts in biliary stone diseases. Abdom Imaging 1993;18(2):145-9.

10. Holzinger F, Z'graggen K, Büchler MW. Mechanisms of biliary carcinogenesis: a pathogenetic multi-stage cascade towards cholangiocarcinoma. Ann Oncol 1999;10 Suppl 4:122-6.

11. Donato F, Gelatti U, Tagger A, et al. Intrahepatic cholangiocarcinoma and hepatitis $\mathrm{C}$ and $\mathrm{B}$ virus infection, alcohol intake, and hepatolithiasis: a case- 
control study in Italy. Cancer Causes Control 2001 Dec;12(10):959-64.

12. Ohta T, Nagakawa T, Ueda N, Mucosal dysplasia of the liver and the intraductal variant of peripheral cholangiocarcinoma in hepatolithiasis. Cancer 1991 Nov 15;68(10):2217-23.

Access full text article on other devices

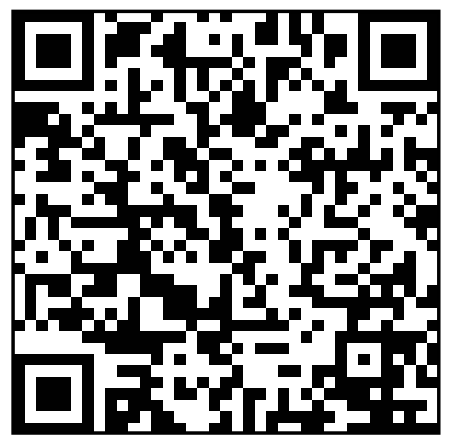

Access PDF of article on other devices

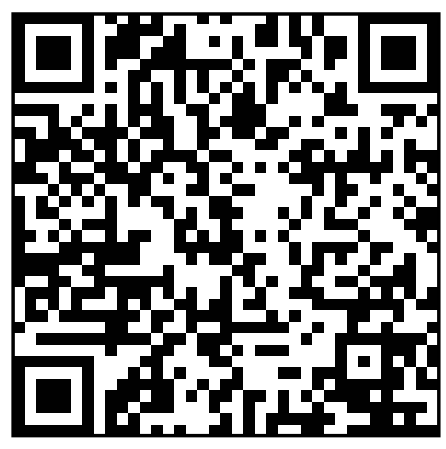

